Gut, 1979, 21, 128-132

\title{
Ileal excretion and bacterial modification of bile acids and cholesterol in patients with continent ileostomy
}

\author{
R M KAY*, Z COHEN, K P SIU, C N PETRUNKA, AND S M STRASBERG \\ From the Departments of Surgery, Toronto Western Hospital and Toronto General Hospital, University of \\ Toronto, Toronto, Canada
}

SUMMARY Bile acid (acidic sterol) and neutral steroid excretion were determined in 15 patients, five with conventional ileostomy, five with continent ileostomy, and five with continent ileostomy and an ileal resection. Acidic sterol losses were normal in conventional ileostomy patients and not significantly increased in those with continent ileostomy alone. Bile acid excretion rates were significantly increased in patients with a continent ileostomy and an ileal resection. Neutral steroid excretion was similar in all groups and not different from normal. Deoxycholic acid was not detected in ileal effluent of patients with conventional ileostomy and less than $2 \%$ of neutral steroid excreted was in the form of bacterial metabolites of cholesterol. The same was true of six of the 10 patients with continent ileostomies; in the other four patients at least $10 \%$ of acidic or neutral steroids were excreted as secondary bile acids or as coprostanol. Modification of steroids was not related to ileal resection. Continent ileostomy was associated with a significant increase in percentage water content and a reduction in the $\mathrm{pH}$ of ileal effluent.

The continent ileostomy, introduced by Kock, ${ }^{1}$ is a surgically-constructed intestinal reservoir which obviates the need for an external appliance. Although the technique provides considerable psychosocial advantage to the patient, the long-term clinical and metabolic consequences remain to be evaluated. In particular, there is little information on the effect of the continent ileal pouch on bile acid and neutral steroid excretion and bacterial modification of these compounds.

Unlike the conventional ileostomy, the continent reservoir inhibits flow of ileal contents. Ileal stasis results in significant alterations in gut ecology. Bacterial growth is enhanced, predominantly anaerobic species including those capable of bile acid conversion. ${ }^{2}{ }^{3}$ Secondly, intestinal stasis increases the duration of contact between substrate and bacterial enzymes, thus increasing the opportunity for steroid modification. Enhanced fermentation of polysaccaride residue may also occur with alteration of the $\mathrm{pH}$ of the lower ileum, possibly affecting the activity of enzymes acting on steroids. Morphological changes such as shortening of the villi have also been

*Address for correspondence: R M Kay, Room 1223, Toronto Western Hospital, 399 Bathurst St., Toronto, Canada, M5T 2S8.

Received for publication 10 August 1979 described in the continent ileostomy. ${ }^{4}$ As a result of these effects, bile acid absorption and ileal secretion of water and electrolytes may be altered.

The present study was designed to determine the influence of the continent ileostomy on total bile acid and neutral steroid excretion. The effect of the intra-abdominal reservoir on the production of bacterially modified steroids and on the $\mathrm{pH}$ and water content of the ileal effluent was also examined. Patients with and without associated ileal resection were studied.

\section{Methods}

SUBJECTS AND TECHNIQUES OF SAMPLE COLLECTION

Fifteen patients were studied. The indication for colon resection was ulcerative colitis in 14 and multiple polyposis in one. No patient had ileal disease. The postoperative period was in all cases greater than four months and all patients were in good health at the time of the study. No antibiotics, lipid-active medications, constipating drugs, or agents known to alter intestinal motility were being taken.

Five patients having a conventional ileostomy without ileal resection (three female, two male, aged 23 to 50 years) were admitted to hospital for collection of ileal effluent. Normal exercise was 
encouraged. Each was given a weight maintenance diet containing $35 \%$ fat calories and $350 \mathrm{mg} / \mathrm{d}$ cholesterol. The ileostomy bag was emptied every two hours during the day and every four hours during the night, samples were frozen immediately. A three-day collection was pooled for analysis.

Five subjects with a continent ileostomy without ileal resection (three female, two male, aged 18 to 30 years) and five subjects in whom the same operation had been associated with (four) or preceded by (one) an ileal resection $(9.4 \mathrm{~cm} \pm 2 \cdot 8$ SEM) (three female, two male, aged 16 to 51 years) were studied under ambulant conditions. Three patients had had the continent ileostomy performed at the time of proctocolectomy, one in the group with ileal resection. Four patients had had indications for ileostomy revision such as a flat stoma, intermittent adhesive obstruction of the terminal ileum, or severe rectal ulcerative colitis in one patient with an ileorectal anastomosis. In all cases the major reason for choosing the continent ileostomy was the psychological and social advantages of the procedure. Each patient was given instructions to consume a normal diet $(35 \%$ fat calories, $350 \mathrm{mg} / \mathrm{d}$ cholesterol). A complete record was made of all food and beverage consumed during the four-day study period and nutrient intakes calculated. Subjects were instructed to empty the ileal pouch according to their usual schedule. Effluent was quantitatively collected in glass jars and immediately frozen. Two subjects were unable to freeze one sample. In these cases the whole collection on that day was discarded resulting in three-day pooled collections. For all other subjects, the four-day collection was pooled for analysis. Markers were not given, as Miettinen and Peltokallio ${ }^{5}$ have demonstrated that correction for faecal flow is not required in the absence of the colon.

\section{CHEMICAL ANALYSES}

Each three or four day collection was pooled, weighed, and thoroughly homogenised at $2^{\circ} \mathrm{C}$ in a Waring blender. An aliquot was taken for determination of $\mathrm{pH}$. Other aliquots were weighed, freeze-dried, and water content determined. The freeze-dried samples were finely ground in a coffeemill. A known amount of 23-nordeoxycholic acid and $5 \alpha$-cholestane was added to weighed aliquots of freeze-dried stool. Faecal steroids were extracted in acetic acid-toluene. ${ }^{6}$ Bile acids were subjected to solvolysis and enzymatic hydrolysis. Neutral steroids were extracted in hexane. The free bile acid phase was then acidified and extracted with diethyl ether and ethyl acetate. The purified bile acids were dried at low temperature, methylated, and acetylated ${ }^{7}$ for analysis by gas-liquid chromatography (GLC)
( $3 \%$ OV-210, $240^{\circ} \mathrm{C}$ isothermal). Results were calculated from the ratios of bile acid to internal standard using pure reference bile acid standards carried through the whole procedure. Recoveries of free and conjugated bile acids added to wet stool before freeze drying ranged from 89 to $99 \%$. The hexane extract, containing neutral steroids was saponified. ${ }^{8}$ Trimethylsilyl derivatives were formed under anhydrous conditions at $20^{\circ} \mathrm{C}$ using Trisyl reagent (Pierce Biochemical) and analysed immediately by GLC $\left(3 \% \mathrm{OV}-17,240^{\circ} \mathrm{C}\right.$ isothermal). As the diets were low in plant sterols prior separa-

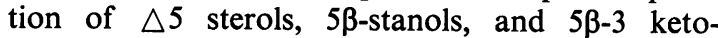
steroids was not found necessary. Separation of cholesterol, coprostanol, coprostanone, and $\beta$-sitosterol was complete. Recoveries of coprostanol and cholesterol added to wet stool were 92 and $86 \%$ respectively.

To determine the ratio of free to conjugated bile acids, an aliquot of the acetic acid/toluene extract was applied to a $0.5 \mathrm{~mm}$ silica gel plate. Free and conjugated bile acids were separated in iso-octane: ethyl acetate: acetic acid: n-butanol $(10: 5: 1.5: 1.5)$ and individually quantified using the hydroxysteroid dehydrogenase enzyme.

\section{STATISTICAL ANALYSES}

Data were analysed by Student's $t$ test. A modified form of this test was used when unequal variances were found to be present. ${ }^{9}$

\section{Results}

\section{CLINICAL DATA}

The study groups are described in Table 1 . There were no significant differences between groups with respect to age, weight, or dietary intake. The daily frequency of pouch emptying was similar for conti-

Table 1 Clinical and dietary characteristics of study groups

\begin{tabular}{|c|c|c|c|}
\hline & \multicolumn{3}{|l|}{ Ileostony } \\
\hline & $\begin{array}{l}\text { Conventional } \\
n=5\end{array}$ & $\begin{array}{l}\text { Continent } \\
n=5\end{array}$ & $\begin{array}{l}\text { Continent } \\
\text { with resection } \\
n=5\end{array}$ \\
\hline Age & $35 \cdot 2$ & $24 \cdot 0$ & $33 \cdot 2$ \\
\hline$(y r)$ & $4 \cdot 9(\mathrm{SEM})$ & $2 \cdot 1$ & $6 \cdot 2$ \\
\hline Weight & $63 \cdot 1$ & $65 \cdot 2$ & $55 \cdot 2$ \\
\hline$(\mathrm{kg})$ & $2 \cdot 1$ & $9 \cdot 1$ & 3.0 \\
\hline Energy intake & $140 \cdot 3$ & $150 \cdot 4$ & $140 \cdot 7$ \\
\hline$(\mathrm{KJ} / \mathrm{kg} / \mathrm{d})$ & $16 \cdot 8$ & 16.4 & $15 \cdot 5$ \\
\hline Protein intake & 1.65 & $1 \cdot 22$ & $1 \cdot 32$ \\
\hline$(\mathrm{g} / \mathrm{kg} / \mathrm{d})$ & $0 \cdot 15$ & $0 \cdot 13$ & $0 \cdot 17$ \\
\hline Carbohydrate intake & $3 \cdot 72$ & $4 \cdot 01$ & $3 \cdot 40$ \\
\hline$(\mathrm{g} / \mathrm{kg} / \mathrm{d})$ & 0.51 & 0.56 & 0.56 \\
\hline Fat intake & $1 \cdot 32$ & $1 \cdot 63$ & $1 \cdot 41$ \\
\hline$(\mathrm{g} / \mathrm{kg} / \mathrm{d})$ & $0 \cdot 18$ & 0.25 & 0.20 \\
\hline Cholesterol intake & $6 \cdot 3$ & $5 \cdot 3$ & $5 \cdot 8$ \\
\hline$(\mathrm{mg} / \mathrm{kg} / \mathrm{d})$ & $0 \cdot 1$ & 0.9 & 0.8 \\
\hline
\end{tabular}


Table 2 Mass, water content, and pH of ileal effluent

\begin{tabular}{|c|c|c|c|}
\hline & \multicolumn{3}{|l|}{ Ileostomy } \\
\hline & Conventional & Continent & $\begin{array}{l}\text { Continent } \\
\text { with resection }\end{array}$ \\
\hline Wet weight & $7 \cdot 61$ & $10 \cdot 52$ & $13 \cdot 67^{*}$ \\
\hline$(\mathrm{g} / \mathrm{kg} / \mathrm{d})$ & 0.89 (SEM) & $2 \cdot 24$ & $2 \cdot 91$ \\
\hline Dry weight & 0.802 & 0.694 & 1.058 \\
\hline$(\mathrm{g} / \mathrm{kg} / \mathrm{d})$ & 0.064 & 0.089 & 0.239 \\
\hline \multirow[t]{2}{*}{ Percent water } & $89 \cdot 2$ & $93 \cdot 2^{*}$ & $92 \cdot 2^{*}$ \\
\hline & 0.8 & 0.7 & 0.5 \\
\hline \multirow[t]{2}{*}{$\mathrm{pH}$} & $7 \cdot 20$ & $6 \cdot 10^{*}$ & $5 \cdot 74 *$ \\
\hline & $0 \cdot 18$ & $0 \cdot 19$ & $0 \cdot 34$ \\
\hline
\end{tabular}

*Significantly different from conventional ileostomy $(\mathbf{P}<0.05)$.

nent ileostomy subjects with $(3 \cdot 8 \pm 0 \cdot 6$ SEM) and without $(3 \cdot 1 \pm 0 \cdot 3)$ resection.

\section{ILEAL EXCRETION OF WATER AND PH OF EFFLUENT}

The wet weight of ileal excreta was significantly greater in the continent ileostomy group with resection compared with subjects with conventional ileostomy (Table 2). However, the dry weight of output was not significantly altered. In both groups of continent ileostomy subjects, the percentage water content of excreta was increased $(P<0.05)$. Continent ileostomy was also associated with a significant reduction in the $\mathrm{pH}$ of ileal effluent (Table 2).

\section{BILE ACID (ACIDIC STEROL) AND NEUTRAL} STEROID EXCRETION

Total acidic sterol excretion was slightly but not significantly greater in patients with continent ileostomy without resection compared with those with conventional ileostomy (Table 3). In both groups, bile acid output was within the normal range described for persons with a normal gastrointestinal tract. ${ }^{10,}{ }^{11}$ Subjects with continent ileostomy accompanied by ileal resection had a significant increase in bile acid excretion with individual excretion rates of

Table 3 Ileal excretion of acid and neutral steroids

\begin{tabular}{|c|c|c|c|}
\hline & \multicolumn{3}{|l|}{ Ileostomy } \\
\hline & Conventional & Continent & $\begin{array}{l}\text { Continent } \\
\text { with resection }\end{array}$ \\
\hline \multicolumn{4}{|l|}{ Acidic sterols } \\
\hline Bile acid excretion & $5 \cdot 63$ & $7 \cdot 61$ & $19 \cdot 82^{*}$ \\
\hline rate $(\mathrm{mg} / \mathrm{kg} / \mathrm{d})$ & $1 \cdot 37(\mathrm{SEM})$ & 0.99 & $5 \cdot 86$ \\
\hline \multicolumn{4}{|l|}{ Cholic acid } \\
\hline ( + metabolites) & $1 \cdot 58$ & 1.94 & $2 \cdot 23^{*}$ \\
\hline $\begin{array}{l}\text { Chenodeoxycholic acid } \\
\text { ( + metabolites) }\end{array}$ & $0 \cdot 17$ & 0.42 & $0 \cdot 30$ \\
\hline Percent deconjugated & $77 \cdot 1$ & $95 \cdot 3$ & $92 \cdot 0$ \\
\hline \multicolumn{4}{|c|}{ Neutral steroids } \\
\hline \multicolumn{2}{|c|}{ Neutral steroid excretion $14 \cdot 70$} & $14 \cdot 99$ & $11 \cdot 37$ \\
\hline rate $(\mathrm{mg} / \mathrm{kg} / \mathrm{d})$ & $2 \cdot 81$ & $0 \cdot 84$ & $1 \cdot 82$ \\
\hline
\end{tabular}

*Significantly different from conventional ileostomy $(\mathrm{P}<0 \cdot 05)$. up to eight times the mean of the control group. A significant increase in the excretion ratio of cholic acid to chenodeoxycholic acid accompanied the higher bile acid output in this group (Table 3 ).

Modification of bile acids occurred in all groups as evidenced by the presence of deconjugated bile acids. Two patients with conventional ileostomies had less than $70 \%$ deconjugation of bile acids; deconjugation was greater than $85 \%$ in the remaining three subjects. Dehydroxylation of bile acids was minor in subjects with conventional ileostomy. No faecal deoxycholic acid was detected in this group and lithocholic acid accounted for less than $10 \%$ of total bile acid. Seven of 10 patients with continent ileostomies also had no deoxycholic acid detected. However, three of the 10 continent ileostomy subjects excreted substantial amounts of secondary bile acids including both lithocholic acid (4 to $22 \%$ of total) and deoxycholic acid (9 to $37 \%$ of total).

Neutral steroid excretion was similar in all groups and similar to that described in patients with an intact colon. ${ }^{11,12}$ Cholesterol metabolites (coprostanol, coprostanone) were present only in trace amounts in the excreta of subjects with conventional ileostomy. In contrast, in one patient in each of the continent ileostomy groups 13 and $27 \%$ of total neutral steroid was present as coprostanol. One of these two subjects also excreted significant amounts of secondary bile acid. Other patients with continent ileostomy excreted less than $2 \%$ of neutral steroid in a bacterially modified form. In summary, six of the 10 patients with continent ileostomies resembled patients with conventional ileostomies where the

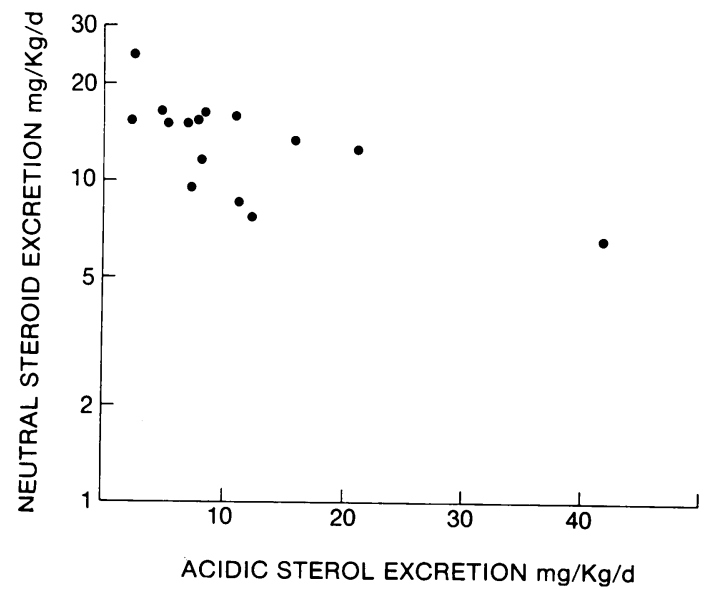

Figure Acidic sterol excretion rate versus log neutral steroid excretion rate. Linear correlation coefficient is 0.670 ( $\mathrm{P}<0.01)$. The correlation coefficient is greater, but not significantly greater, than that obtained when acidic sterol excretion is plotted against neutral steroid excretion. 
formation of deoxycholic acid or cholesterol metabolites was concerned. Four patients with continent ileostomies had significant conversion of steroids. Unlike the increase in the bile acid excretion rate, modification of steroids did not appear to be related to an associated intestinal resection.

The log linear regression of total bile acid versus neutral steroid excretion is shown in the Figure. The results indicate that over the narrow range of bile acid excretion rates measured, neutral steroid output decreases as bile acid excretion rate increases.

\section{Discussion}

\section{BILE ACID EXCRETION}

The present study indicates that ileal bile acid absorption is not greatly compromised in patients with continent ileostomy provided that the remainder of the ileum is intact. Acidic sterol output is in the upper range of normal according to figures available for subjects with an intact colon. ${ }^{11}{ }^{13}$ Our data on conventional ileostomy subjects are in agreement with previous reports that faecal bile acid loss is normal; this suggests that colonic bile acid absorption is quantitatively minor or that adaptation in ileal absorption of bile acids occurs. ${ }^{5}, 14,15$ Bile acid excretion is greatly enhanced in patients in whom a small ileal resection was performed at the time of or before pouch construction. These small resections are apparently not infrequent during the construction of a pouch ileostomy (four of 10 patients in this small series).

Faecal bile acid loss is equal to hepatic bile acid synthesis rate in the steady state. It is likely that these patients were in a steady state four months after surgery and under conditions of energy balance and normal diet. Enhanced bile acid synthesis is usually characterised by an increase in the relative proportion of trihydroxy bile acids in bile. ${ }^{16}$ It is likely that increased bile acid synthesis due to increased faecal loss accounts for the predominance of cholic acid (and its metabolites) in the excreta of resected subjects in the present study.

\section{NEUTRAL STEROID EXCRETION}

Ileal cholesterol excretion was not influenced by the presence of a continent ileostomy. Cholesterol absorption occurs mainly in the jejunum. Apparently bile acid losses were not sufficient to cause cholesterol malabsorption.

\section{MODIFICATION OF BILE ACIDS AND NEUTRAL} STEROIDS

No direct evidence has been presented to prove that the chemical modifications described were bacterially induced; however, this may be reasonably inferred. Previous studies have indicated that there is little bacterial modification of steroids in conventional ileostomies other than deconjugation of bile acids. Secondary bile acids were absent ${ }^{14,17}$ or reduced ${ }^{5}$ $(0-12 \%$ of total) in conventional ileostomy effluent. Miettinen and Peltokallio ${ }^{5}$ also failed to detect neutral steroid metabolites in patients with conventional ileostomies. Our findings are in agreement with this. We were not able to detect any deoxycholic acid and only small amounts of lithocholic acid in the conventional ileostomy group and metabolites of cholesterol were negligible. In two of the five conventional ileostomy patients deconjugation was relatively incomplete.

Deconjugation was almost complete in all patients with continent ileostomies. Substantial bacterial modification of steroids was present in four of 10 patients and was not related to ileal resection. Clearly, bacterial modification is not a direct consequence of pouch construction but occurs in certain patients with continent pouches due to overgrowth with specific bacteria. Anaerobic organisms are lower in ileal effluent than colonic contents ${ }^{18}$ but continent ileostomies are associated with enhanced bacterial growth, especially anaerobic species, including those capable of bile acid dehydroxylation. ${ }^{2,3}$ Although $7 \alpha$-dehydroxylase has a $\mathrm{pH}$ optimum of 7 to 8 , and is apparently inhibited at a pH of 6.0 to $6.5^{19}$ in the present study, secondary bile acids were detected in ileal effluent of $\mathrm{pH} 6.0$ to 6.2. The continent ileostomy was associated with a decrease in effluent $\mathrm{pH}$, probably as a result of bacterial fermentation of polysaccharide residue and production of short chain fatty acids within the ileal reservoir.

\section{RELATIONSHIP OF ACIDIC AND NEUTRAL \\ STEROID EXCRETION}

Cholesterol intakes for all groups were similar. In these circumstances the negative correlation between bile acid and neutral sterol excretion suggests that, as bile acid synthesis is stimulated, cholesterol excretion into the bile decreases. Such an effect has been previously reported in a primate model. ${ }^{20}$

\section{ILEAL EXCRETION OF WATER}

Patients with continent ileostomy also demonstrated an increase in the water content of ileal effluent. This was not associated with consistent alterations in the excretion or concentration of dihydroxy bile acids. The latter have been shown to enhance secretion of water and electrolytes in the colon. ${ }^{21}$ The ileal concentration of other substances affecting intestinal water flux - that is, long chain fatty acids ${ }^{22}$ - may have been altered. Alternatively, the observed 
increase in water output may have been due to morphological changes in the lower ileum. ${ }^{4}$

\section{CLINICAL IMPLICATIONS}

Construction of a pouch ileostomy is not infrequently associated with a small ileal resection, which may result in increased loss of bile acids. In some cases the magnitude of the loss of bile acids might be sufficient to predispose to cholesterol gallstones as in the case of ileal resections of greater than $10 \mathrm{~cm}$ performed during conventional ileostomy. ${ }^{23}$ Pouch ileitis is an infrequent but troublesome problem. It may be related to the permissive effects of intestinal stasis on bacterial growth. As demonstrated in the present study, significant changes in the $\mathrm{pH}$ and bile acid profile of the ileal contents, which are presumably due to bacterial action, may occur in patients with continent ileostomies. The effect of bacterially modified bile acids or undefined toxic agents in the lower ileum may be augmented by increased duration of contact with the ileal mucosa. Studies of sterol excretion and modification in patients with pouch ileitis are required.

This work was supported by grants from the PSI Foundation and the Medical Research Council of Canada. The authors thank Dr W W H Rudd for his advice and for permission to study several of his patients and Ms L Berndl, MSc, RPDt, for assistance with the nutritional studies.

\section{References}

${ }^{1}$ Kock NG. Intra-abdominal 'reservoir' in patients with permanent ileostomy. Arch Surg 1969; 99:223-31.

${ }^{2}$ Brandberg A, Kock NG, Philipson B. Bacterial flora in intra-abdominal ileostomy reservoir. Gastroenterology 1972;63:413-6.

${ }^{3}$ Schjønsby $\mathbf{H}$, Halvorsen JF, Hofstad T, Hovdenak N. Stagnant loop syndrome in patients with continent ileostomy (intra-abdominal ileal reservoir). Gut 1977; 18:795-9.

${ }^{4}$ Philipson B, Brandberg A, Jagenburg R, Kock NG Lageı I, Ahren C. Mucosal morphology, bacteriology, and absorption in intra-abdominal ileostomy reservoir. Scand J Gastroenterol 1975;10:145-53.

${ }^{5}$ Miettinen TA, Peltokallio P. Bile salt, fat, water, and vitamin B12 excretion after ileostomy. Scand J Gastroenterol $1971 ; 6: 543-52$.

${ }^{6}$ Evrard E, Janssen G. Gas-liquid chromatographic determination of human fecal bile acids. J Lipid Res 1968;9:226-36.
${ }^{7}$ Roovers J, Evrard E, Vanderhaeghe H. An improved method for measuring human blood bile acids. Clin Chim Acta 1968;19:449-57.

${ }^{8}$ Roseleur OJ, Van Gent CM. A simplified method for the determination of steroids in diets and faeces. Clin Chim Acta 1978; 82:13-23.

${ }^{9}$ Snedecor GW, and Cochran WG. Statistical Methods. 6th ed. Ames, Iowa: Iowa State University Press, 1967: 114.

${ }^{10}$ Grundy SM, Ahrens EH, Miettinen TA. Quantitative isolation and gas-liquid chromatographic analysis of total fecal bile acids. J Lipid Res 1965;6:397-410.

${ }^{11}$ Miettinen TA. Current views on cholesterol metabolism. Horm Metab Res 1974;Suppl 4:37-44.

${ }^{12}$ Miettinen TA, Ahrens EH, Grundy SM. Quantitative isolation and gas-liquid chromatographic analysis of total dietary and fecal neutral steroids. J Lipid Res $1965 ; 6: 411-24$.

${ }^{13}$ Kay RM, Truswell AS. The effect of citrus pectin on blood lipids and fecal steroid excretion in man. $A m J$ Clin Nutr 1977;30:171-6.

${ }^{14}$ Percy-Robb IW, Jalan KN, McManus JPA, Sircus W: Effect of ileal resection on bile salt metabolism in patients with ileostomy following proctocolectomy. Clin Sci 1971;41:371-82.

${ }^{15}$ Huibregtse K, Hoek F, Sanders GTB, Tytgat GNJ. Bile acid metabolism in ileostomy patients. Eur $J$ Clin Invest 1977;7:137-40.

${ }^{16}$ Garbutt JT, Kenney TJ. Effect of cholestyramine on bile acid metabolism in normal man. J Clin Invest. 1972;51:2781-9.

${ }^{17}$ Percy-Robb IW, Telfer Brunton WA, Gould JC, Jalan KN, McManus JPA, Sircus W. Composition and bile salt transforming capacity of the bacterial flora of ileal effluent in patients with ileostomies. Scand $J$ Gastroenterol 1971 ; 6: 625-30.

${ }^{18}$ Gorbach SL, Nahas L, Weinstein L. Studies of intestinal microflora IV. The microflora of ilestomy effluent: a unique microbial ecology. Gastroenterology 1967;53: 874-80.

${ }^{19}$ Midtvedt T, Norman A. Parameters in 7 $\alpha$-dehydroxylation of bile acids by anaerobic lactobacilli. Acta Path Microbiol Scand (A) 1968; 72:313-29.

${ }^{20}$ Strasberg SM, Petrunka CN, Ilson RG. Effect of bile acid synthesis rate on cholesterol secretion rate in the steady state. Gastroenterology 1976;71:1067-70.

${ }^{21}$ Mekhjian HS, Phillips SF, Hofmann AF. Colonic secretion of water and electrolytes induced by bile acids: perfusion studies in man. J Clin Invest $1971 ; 50$ : 1569-77.

${ }^{22}$ Ammon HV, Phillips SF. Inhibition of ileal water absorption by intraluminal fatty acids. $J$ Clin Invest 1974;53:205-10.

${ }^{23}$ Hill GL, Mair WSJ, Goligher JC. Gallstones after ileostomy and ileal resection. Gut 1975; 16:932-6. 